\title{
Antifungals Patterns in Critical Patients with Candidiasis in the Intensive Care Units at Sanglah General Hospital 2019
}

Komang Ady Widayana',

I Wayan Aryabiantara ${ }^{2}$, Tjokorda Gde Agung Senapathi², IWayan Suranadi², I Gusti Ngurah Mahaalit Aribawa ${ }^{2}$

' Medical Education Program, Faculty of Medicine, Udayana University, Denpasar-Bali, Indonesia

${ }^{2}$ Department of Anesthesiology, Pain Management, and Intensive Care, Faculty of Medicine, Udayana University, Sanglah General Hospital, Denpasar-Bali, Indonesia

\section{Cite this article:}

Ady Widayana K, Aryabiantara IW, Senapathi TGA, Suranadi IW, Aribawa IGNM. Antifungals patterns in critical patients with candidiasis in the intensive care units at Sanglah General Hospital 2019. Neurologico Spinale Medico Chirurgico. 2019;2(3): 49-52. DOI:I0.36444/ nsmc.v2i3.83

Corresponding author:

I Gusti Ngurah Mahaalit Aribawa

IDepartment of Anesthesiology,

Pain Management, and Intensive Care,

Faculty of Medicine, Udayana University,

Sanglah General Hospital,

Denpasar-Bali, Indonesia

Jalan Diponegoro, Denpasar, Indonesia mahaalit@unud.ac.id

\begin{abstract}
Introduction: The prompt initiation of appropriate antifungal therapy is essential in controlling invasive candidiasis and improving the prognosis in critical patients undergoing treatment in the Intensive Care Unit. Candida Score (CS) can assess patients at risk of candidiasis and is expected to assist clinicians in starting antifungal therapy in patients suspected Candidiasis. The purpose of this study was to determine the pattern of antifungal administration in critically ill patients with candidiasis in the Intensive Care Unit at Sanglah General Hospital.

Methods: The design of this study is a cross-sectional descriptive study involving critically ill patients who were under treatment in the Intensive Care Unit of Sanglah General Hospital from January to June 2019. The patients included in this study were patients who were $\geq 18$ years old and under treatment in ICU for at least seven days.

Results: There are 64 patients undergoing treatment in the Intensive Care Unit. From 64 patients, 6 pasien had $\mathrm{CS}=0,29$ patients had $\mathrm{CS}=1,13$ patients had $\mathrm{CS}=2,11$ patients had $\mathrm{CS}=3,5$ patients had $\mathrm{CS}=4$, and no patients had $\mathrm{CS}=5$. Eleven patients received empirical antifungal therapy. All empirical antifungal therapies use the Triazole group.

Conclusion: We found that 11 of 16 patients with a CS value of $\geq 2.5$ were given empirical antifungal therapy, while 48 patients with a CS value of $<2.5$ were not given empirical antifungal therapy.
\end{abstract}

Keywords: Invasive Candidiasis, Candida Score, Empirical Antifungal Therapy.

\section{Introduction}

Candida species are one of the most common pathogens that infect patients in hospitals, especially in the Intensive Care Unit (ICU). ${ }^{1}$ Candidiasis is causing significant mortality and morbidity. ${ }^{2}$ The incidence of candidiasis is quite high in the Intensive Care Unit. It has been reported that Candida ranks third as the most frequently infecting species in ICU, and about 843 (17\%) of the 4947 patients treated at ICU were infected with Candida species. ${ }^{3}$ Candidiasis often causes death in patients in the hospital, especially in ICU. Mortality rates related to candidiasis can reach $40-70 \%$ in ICU. ${ }^{4-6}$

This high mortality rate is caused by the difficulty of establishing an early diagnosis. Immediate initiation of suitable antifungal therapy is essential for controlling candidiasis, and this has been shown to reduce mortality. ${ }^{7}$ Guidelines are needed in providing appropriate antifungal therapy and to avoid the use of unnecessary antifungal therapy.

Candida Score (CS) can assess patients who are at risk of infection with candidiasis and, in their assessment use four risk factors, namely: multifocal Candida colonization, severe septic 
/ septic shock, surgery, and total parenteral nutrition. ${ }^{8}$ This Candida Score is expected to help clinicians to start antifungal therapy so there is no excessive use of antifungal therapy associated with increased health costs and the development of resistance from Candida, and the lack of use of antifungal therapy associated with worsening prognosis in critically ill patients. ${ }^{8-10}$

\section{Methods}

This study is a cross-sectional descriptive study involving critically ill patients who were under treatment in the Intensive Care Unit of Sanglah General Hospital, Denpasar-Bali, Indonesia, from January to June 2019. The sample collection technique used in this study is a total sampling. The patients included in this study were patients who were $\geq 18$ years old and under treatment in ICU for at least seven days. Exclusion criteria were as follows: neutropenia defined as a total leukocyte count $<500 / \mathrm{mm} 3$, mothers who are breastfeeding or pregnant women, patients who infected with Candida species or currently on antifungal therapy for the first seven days in ICU. This study protocol was approved by the Committee of Ethical Research of Udayana University/Sanglah General Hospital. The data that have been collected and categorized are analyzed using IBM SPSS Statistics version 23 software.

\section{Results}

Sixty-four patients were included in this study. The most common age group was $60-69$ years and the male-to-female ratio was 1.37:1. Patient characteristics such as age, gender, diagnosis on ICU admission, Apache II Score and ICU length of stay are shown in Table 1.

Table 1. Characteristic of the patients

\begin{tabular}{|c|c|}
\hline Characteristics & $N=64$ \\
\hline \multicolumn{2}{|l|}{ Age $(\%)$} \\
\hline$<20$ Years & $4(6.25)$ \\
\hline $20-29$ Years & $6(9.38)$ \\
\hline $30-39$ Years & $4(6.25)$ \\
\hline $40-49$ Years & $12(18.75)$ \\
\hline $50-59$ Years & $12(18.75)$ \\
\hline $60-69$ Years & $16(25)$ \\
\hline $70-79$ Years & $9(14.06)$ \\
\hline$\geq 80$ Years & $1(1.56)$ \\
\hline \multicolumn{2}{|l|}{ Gender (\%) } \\
\hline Male & $37(57.8)$ \\
\hline Female & $27(42.2)$ \\
\hline \multicolumn{2}{|c|}{ Diagnosis of ICU admission (\%) } \\
\hline Surgical & $39(60.9)$ \\
\hline Non-Surgical & $25(39.1)$ \\
\hline \multicolumn{2}{|l|}{ Apache II Score } \\
\hline$\geq 15$ & $44(68.8)$ \\
\hline$<15$ & $20(31.2)$ \\
\hline \multicolumn{2}{|l|}{ ICU Length of stay } \\
\hline Median (Min-Max) & 11.5 (7-48) days \\
\hline
\end{tabular}

Table 2. Distribution variable of Candida Score

\begin{tabular}{|c|c|c|c|c|c|}
\hline \multirow{2}{*}{ Variable of Candida Score } & \multicolumn{5}{|c|}{ Value of Candida Score } \\
\hline & $\begin{array}{c}1 \\
(n=29)\end{array}$ & $\begin{array}{c}2 \\
(n=13)\end{array}$ & $\begin{array}{c}3 \\
(n=11)\end{array}$ & $\begin{array}{c}4 \\
(n=5)\end{array}$ & $\begin{array}{c}5 \\
(\mathrm{n}=0)\end{array}$ \\
\hline Total parenteral Nutrition & 4 & 11 & 3 & 5 & 0 \\
\hline Severe Sepsis / Septic Shock & 0 & 2 & 11 & 5 & 0 \\
\hline Multifocal Candida Colonization & 0 & 0 & 1 & 1 & 0 \\
\hline Surgery & 25 & 11 & 7 & 4 & 0 \\
\hline
\end{tabular}

In this study we found the distribution of Candida Score values as follows: 6 patients had $\mathrm{CS}=0 ; 29$ patients had $\mathrm{CS}=1 ; 13$ patients had $\mathrm{CS}=2 ; 11$ patients had $\mathrm{CS}=3 ; 5$ patients had $\mathrm{CS}=4$; and no patient had $\mathrm{CS}=5$. Table 2 shown the distribution variable of Candida Score. The distribution as follows: 47 (73.4\%) patients were postoperative patients; 23 (35.9\%) patients used total parenteral nutrition; 18 (28.1\%) patients had severe sepsis / septic shock; and 2 (3.1\%) patients had multifocal Candida colonization

Table 3. Value of Candida Score according to the empirical antifungals treatments

\begin{tabular}{cccc}
\hline \multirow{2}{*}{$\begin{array}{c}\text { Value of } \\
\text { Candida Score }\end{array}$} & \multicolumn{2}{c}{ Initiation of Empirical Antifungal Therapy } & \\
\cline { 2 - 3 } Total \\
\hline 0 & 0 & Not Given & \\
\hline 1 & 0 & 6 & 6 \\
2 & 0 & 29 & 29 \\
3 & 8 & 13 & 13 \\
4 & 3 & 3 & 11 \\
5 & 0 & 2 & 5 \\
\hline
\end{tabular}

From this study, we found that empirical antifungal therapy was initiated in 11 of $16(68.7 \%)$ patients with Candida Score $\geq 2.5$ and no empirical antifungal therapy was initiated in 48 patients with $\mathrm{CS}<$ 2.5. All empirical antifungal therapies used the Triazole group.

Thirty-six (56\%) patients died during their ICU stay. Among the 11 patients who were given empirical antifungal therapy, 9 (81.8\%) died, whereas among 53 patients who were not given antifungal therapy, $27(50.9 \%)$ died.

Table 4. Outcome of the patient according to the initiation of empirical antifungal therapy

\begin{tabular}{lccc}
\hline Initiation of Empirical & \multicolumn{2}{c}{ Outcome } & \multirow{2}{*}{ Total } \\
\cline { 2 - 3 } Antifungal Therapy & Alive & Dead & \\
\hline Given (Triazole) & 2 & 9 & 11 \\
Not Given & 26 & 27 & 53 \\
\hline
\end{tabular}




\section{Discussion}

Candida Score is a simple scoring system that may help clinicians in differentiating between invasive Candidiasis and Candida species colonization in non-neutropenic critically ill patients. ${ }^{8,9}$ Candida Score can also be used as a reference in starting empirical antifungal therapy. ${ }^{9}$ Candida Score had a sensitivity of $81 \%$ and a specificity of $74 \%$ with a cut-off value of $2.5 .^{8}$

In this study, $16(25 \%)$ patients had a CS value $>2.5$ and 48 (75\%) patients had a CS value $<2.5$. Similar results are also founded in the study conducted by León et al. León et al., ${ }^{9}$ reported that there were 327 (36.65\%) patients who had a Candida Score $\geq 3$. However, different results were reported by Leroy et al. Leroy et al., ${ }^{10}$ reported that patients with a Candida Score $\geq 3$ had the highest percentage of $53.19 \%$. The difference in these results can occur because one of the inclusion criteria in a study conducted by Leroy et al. was severe septic or septic shock so that the patients in the study had a minimum value of Candida Score is two. ${ }^{10}$

Empirical antifungal therapy was only given to $11(68.8 \%)$ of 16 patients who had a Candida Score $\geq 2.5$, whereas empirical antifungal therapy was not given to all patients with a Candida Score < 2.5. These results are different from the previous study conducted by Leroy et al. Leroy et al., ${ }^{10}$ found that 18 (36\%) of 50 patients with CS values $\geq 2.5$ and $1(2.3 \%)$ of 44 patients with CS values $<2.5$ received empirical antifungal therapy. This difference in results can be caused by the decision of the doctor in charge of the patient. The use of the antifungal agent for the treatment of candidiasis should take into account the history of intolerance to an antifungal agent, the dominant Candida species and current susceptibility data in a particular clinical unit, the severity of illness, relevant comorbidities, and evidence of involvement of the CNS, cardiac valves or visceral organs. ${ }^{11}$ The doctor must also consider the risks of toxicity, cost-effectiveness, the patient's willingness to be given antifungal therapy, and whether the patient is pregnant or not. ${ }^{11}$

Leroy et al., ${ }^{10}$ in their study, found that $10(53 \%)$ of 19 patients given empirical antifungal therapy died and $36(48 \%)$ of 75 patients who were not given antifungals died during their ICU stay. They also found that mortality in patients who had CS $>3$ and received empirical antifungal therapy was no different from patients who had CS $>$ 3 and did not receive empirical antifungal therapy (6/10 vs. 7/11; $p=$ 1). In this study, empirical antifungal therapy was given to 11 patients and $9(80.8 \%)$ of them died, whereas empirical antifungal therapy was not given to 53 patients and 27 (50.8\%) of them died.

The risk of mortality among patients with candidiasis related to increasing age, higher APACHE II scores, infecting Candida species, immunosuppressive agents, and antifungal selection. ${ }^{11}$ In this study, the characteristics of patients with the age group 60-69 years had the highest percentage of $25 \%$. Besides, patients with Apache II Score $\geq 15$ also had the highest percentage of $68.8 \%$. In our opinion, these two characteristics of our subject might have contributed to the high mortality rate in this study. Also, the use of the Triazole group as empirical antifungal therapy can increase the risk of death in this study. Based on Infectious Diseases Society of America guideline, preference should be given to an echinocandin in hemodynamically unstable patients, in those colonized with Azole-resistant Candida species and those previously exposed to an Azole antifungal group. Fluconazole may be considered in hemodynamically stable patients who have no prior exposure to Azoles antifungal group or who are colonized with Azole-susceptible Candida species. The Echinocandins group demonstrates significant fungicidal activity against most Candida species, and each of these agents has demonstrated success in approximately $70-75 \%$ of patients. ${ }^{11}$ The Echinocandins group has exceptional efficacy, limited drug interactions, a good safety profile, and concerns about fluconazole resistance, leading many experts to choose echinocandins as initial therapy for most adult patients with candidiasis. ${ }^{11}$ Only one study comparing an Echinocandin group to Fluconazole has been performed, and the results from this study was Anidulafungin suggest a strong trend toward more favorable outcomes compared with Fluconazole as primary therapy for candidiasis. ${ }^{12}$ A combined analysis of 7 of the largest randomized clinical trials comparing treatment for candidemia and invasive candidiasis and involving almost 2000 patients found that initial therapy with an Echinocandin was a significant predictor of survival. ${ }^{13}$ However, this is still the author's opinion so that further research needs to be done related to resistance and susceptible patterns of antifungal agent in the ICU Sanglah General Hospital, Denpasar, Bali, Indonesia.

This study has limitations such as the lack of samples used in this study when compared to the number of samples conducted by Leroy et al..$^{10}$ and León et al..$^{9}$. The small number of samples was because this study was only conducted at one tertiary type hospital in Bali, and data were also taken from patients undergoing treatment in the Intensive care Unit from January to June 2019. In addition, prospective research is needed to find out reasons why doctors do not give empirical antifungal therapy to patients who have a Candida Score $>$ 2.5 and the incidence rate of candidiasis in the ICU Sanglah General Hospital.

\section{Conclusion}

The pattern of antifungal administration in critically ill patients with candidiasis in Sanglah General Hospital has relevance to Candida Score. In this study was found that 11 of 16 patients with a CS value $>2.5$ were given empirical antifungal therapy, while 48 patients with a CS value of $<2.5$ were not given empirical antifungal therapy.

\section{Acknowledgment}

The authors report no conflict of interest.

\section{References}

1. Guo F, Yang Y, Kang Y, et al. Invasive candidiasis in intensive care units in China: a multicentre prospective observational study. J Antimicrob Chemother. 2013;68:1660-1668. DOI:10.1093/jac/dkt083 
2. Guzman JA, Tchokonte R, Sobel JD. Septic Shock Due to Candidemia: Outcomes and Predictors of Shock Development. J Clin Med Res. 2011;3(2):65-71. DOI:10.4021/jocmr536w

3. Vincent J, Rello J, Marshall J, et al. International Study of the Prevalence and Outcomes of Infection in Intensive Care Units. JAMA. 2009;302(21):2323-2329. DOI:10.1001/jama.2009.1754.

4. Lortholary $\mathrm{O}$, Renauat $\mathrm{C}$, Sitbon $\mathrm{K}$, et al. Worrisome trends in incidence and mortality of candidemia in intensive care units. Intensive Care Med. 2014;40:1303-1312. DOI:10.1007/s00134-014-3408-3

5. Kett DH, Azoulay E, Echeverria PM, et al. Candida bloodstream infections in intensive care units: Analysis of the extended prevalence of infection in intensive care unit study*. Crit Care Med. 2011;39(4):665670. DOI:10.1097/CCM.0b013e318206c1ca

6. Bassetti M, Ansaldi F, Diaz-martin A, et al. A multicenter study of septic shock due to candidemia: outcomes and predictors of mortality. Intensive Care Med. 2014;40:839-845. DOI:10.1007/s00134-014-3310-Z

7. Parkins MD, Sabuda DM, Elsayed S, et al. Adequacy of empirical antifungal therapy and effect on outcome among patients with invasive Candida species infections. J Antimicrob Chemother. 2007;60:613-618. DOI:10.1093/jac/dkm212

8. León C, Ruiz-Santana S, Saavedra P, et al. A bedside scoring system ("Candida score") for early antifungal treatment in nonneutropenic critically ill patients with Candida colonization. Crit Care Med. 2006;34(3):730-737. DOI:10.1097/01.CCM.0000202208.37364.7D
9. León C, Ruiz-santana S, Saavedra P, et al. Usefulness of the "Candida score" for discriminating between Candida colonization and invasive candidiasis in non-neutropenic critically ill patients: A prospective multicenter study. Crit Care Med. 2009;37(5):1624-1633. DOI:10.1097/ CCM.0b013e31819daa14

10. Leroy G, Lambiotte F, Thévenin D, et al. Evaluation of "Candida score" in critically ill patients : a prospective, multicenter, observational, cohort study. Ann Intensive Care. 2011;1(1):50. DOI:10.1186/2110-5820$1-50$.

11. Pappas PG, Kauffman CA, Andes DR, et al. Clinical Practice Guideline for the Management of Candidiasis: 2016 Update by the Infectious Diseases Society of America. Clin Infect Dis. 2016;62(4):1-50. DOI:10.1093/cid/civ933

12. Andes DR, Safdar N, Baddley JW, et al. Impact of Treatment Strategy on Outcomes in Patients with Candidemia and Other Forms of Invasive Candidiasis: A Patient-Level Quantitative Review of Randomized Trials. Clin Infect Dis. 2012;54(8):1110-1122. DOI:10.1093/cid/cis021

13. Reboli AC, Rotstein C, Pappas PG, et al. Anidulafungin versus Fluconazole for Invasive Candidiasis. N Engl J Med. 2007;356(24):24722482. DOI:10.1056/NEJMoa066906 